\title{
DRM 時間差分境界要素法による異方性材料の非定常熱伝導解析
}

\section{Dual Reciprocity Time-Finite-Difference BEM for Transient Heat Conduction in Anisotropic Solids}

\author{
正 田中 正隆 (信州大工) \\ 正 松本 敏郎 (名古屋大院) \\ ○学 原 啓志（信州大院） \\ 学 黒川 浩太郎(信州大院)
}

\begin{abstract}
Masataka TANAKA, Shinshu University, 4-17-1 Wakasato, Nagano 380-8553
Toshiro MATSUMOTO, Nagoya University, Furo-cho, Chikusa-ku, Nagoya

Keiji HARA, Graduate School of Shinshu University

Kotaro KUROKAWA, Graduate School of Shinshu University
\end{abstract}

Key Words: Computational Mechanics, Time-stepping Boundary Element Method, Dual Reciprocity Method,

Transient Heat Conduction, Anisotropic Solid

\section{1. 緒 言}

異方性材料の非定常熱伝導問題に対する境界要素法の定 式化では，異方性材料に対する基本解が必要であり，さらに 導出される境界積分方程式の中に時間ステップごとに見かけ の初期条件に由来する領域積分項が残る。この領域積分を評 価するためには，領域内部を要素またはセルに分割しなけれ ばならないが，領域内部の要素分割にはたいへん手間がかか り境界要素法の特長が半減してしまう(1). また, 定式化の際 に必要となる基本解に時間依存の厳密基本解を用いると, 係 数マトリックスの計算がかなり複雑となり, 計算時間もかか る(1).

そこで本研究では，等方性問題の基本解と時間差分近似を 用いる解法について考察する。ささらに, 等方性問題の基本解 を用いる事と時間差分近似に由来する領域積分項を，二重相

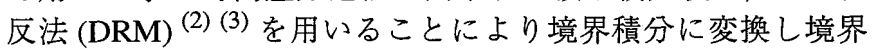
のみの離散化と内部選点のみで解析する.

本報では定式化と開発した解析プログラムによる解析例 を示し, 本手法の有効性とDRM で用いる関数について検討 を行う.

\section{2. 理 論}

異方性材料の 2 次元非定常熱伝導問題に対する支配微分 方程式は，次式で与えられる。

$$
\begin{aligned}
k_{11} \frac{\partial^{2} u(x, t)}{\partial x_{1}{ }^{2}}+k_{22} \frac{\partial^{2} u(x, t)}{\partial x_{2}{ }^{2}}+2 k_{12} & \frac{\partial^{2} u(x, t)}{\partial x_{1} \partial x_{2}} \\
= & \rho c \dot{u}(x, t)
\end{aligned}
$$

ただし, $u(x, t)$ は温度, $k_{11}, k_{22}, k_{12}$ は 2 階対称の熱伝導 率テンソルの成分である. $\rho$ は密度, $c$ は比熱とし上付きの ドット(·)は時間による微分を表す.

式 (1) に対し等方性問題の基本解を用いるために, 次のよ うに熱伝導テンソルを等方性の部分とその他の部分に分ける.

$$
k_{i j}^{A}=k_{i j}^{I}+k_{i j}^{A-I}
$$

$k_{i j}^{A}=\left[\begin{array}{cc}k_{11} & k_{12} \\ k_{12} & k_{22}\end{array}\right], k_{i j}^{I}=\left[\begin{array}{cc}M & 0 \\ 0 & M\end{array}\right], k_{i j}^{A-I}=\left[\begin{array}{cc}m_{1} & k_{12} \\ k_{12} & m_{2}\end{array}\right]$
ただし， $M$ には任意の材料定数を用いてもよいが，ここで は $k_{11}, k_{22}$ の平均值を用いる. 式 (1) を次式のように表す.

$$
\begin{aligned}
\frac{\partial^{2} u(x, t)}{\partial x_{1}{ }^{2}}+\frac{\partial^{2} u(x, t)}{\partial x_{2}{ }^{2}}=- & \frac{m_{1}}{M} \frac{\partial^{2} u(x, t)}{\partial x_{1}^{2}}-\frac{m_{2}}{M} \frac{\partial^{2} u(x, t)}{\partial x_{2}{ }^{2}} \\
& -2 \frac{k_{12}}{M} \frac{\partial^{2} u(x, t)}{\partial x_{1} \partial x_{2}}+\frac{\rho c \dot{u}(x, t)}{M}
\end{aligned}
$$

式 (3) の右辺をソース項と見なせばこの式は Poisson 方程式 であり, Laplace 方程式の基本解を用いて DRBEM を構築で きる。

次にDRM を適用するため, 式(3)の右辺を次式で近似する.

$$
\begin{array}{r}
-\frac{m_{1}}{M} \frac{\partial^{2} u(x, t)}{\partial x_{1}{ }^{2}}-\frac{m_{2}}{M} \frac{\partial^{2} u(x, t)}{\partial x_{2}{ }^{2}}-2 \frac{k_{12}}{M} \frac{\partial^{2} u(x, t)}{\partial x_{1} \partial x_{2}} \\
+\frac{\rho c \dot{u}(x, t)}{M}=\sum_{\ell=1}^{N+L} \alpha^{\ell} f\left(x, z^{\ell}\right)
\end{array}
$$

たたし， $N$ は境界節点数, $L$ は内部選点数, $\alpha^{\ell}$ は未知係数, $f\left(x, z^{\ell}\right)$ は近似関数, $z^{\ell}$ は DRM 選点を表すものとする. 近 似関数には観測点と DRM 選点との距離の関数を使用する. ここで，次式を満たす特解を $\hat{u}\left(x, z^{\ell}\right)$ とする。

$$
\nabla^{2} \hat{u}\left(x, z^{\ell}\right)=f\left(x, z^{\ell}\right)
$$

この特解 $\hat{u}\left(x, z^{\ell}\right)$ を用いると式 (3) の展開された支配微分方 程式は未知係数 $\alpha^{\ell}$ と特解 $\hat{u}\left(x, z^{\ell}\right)$ により次式のように書き 表すことができる。

$$
\nabla^{2} u(x, t)=\sum_{\ell=1}^{N+L} \alpha^{\ell} \nabla^{2} \hat{u}\left(x, z^{\ell}\right)
$$

上式の両辺に基本解 $u^{*}(x, y)$ をかけ, 考察領域全体で積分し 部分積分することにより次の積分方程式を得る.

$$
\begin{aligned}
& c(y) u(y, t)+\int_{\Gamma} q^{*}(x, y) u(x, t) d \Gamma \\
& -\int_{\Gamma} u^{*}(x, y) q(x, t) d \Gamma=\sum_{\ell=1}^{N+L} \alpha^{\ell}\left\{c(y) \hat{u}\left(y, z^{\ell}\right)\right. \\
& \left.+\int_{\Gamma} q^{*}(x, y) \hat{u}\left(x, z^{\ell}\right) d \Gamma-\int_{\Gamma} u^{*}(x, y) \hat{q}\left(x, z^{\ell}\right) d \Gamma\right\}
\end{aligned}
$$

ただし， $c(y)$ はソース点のある境界形状で決まる定数であ り, $y \in \Omega$ のときには $c(y)=1$ となる.また, $\hat{q}\left(x, z^{\ell}\right)$ は特 
解 $\hat{u}\left(x, z^{\ell}\right)$ の法線方向勾配を表す. 次に, 異方性問題の熱流 束を導入する．異方性問題に対する熱流束は次式で定義さ れる。

$$
\begin{aligned}
q^{A}(x, t) & =-k_{i j}^{A} \frac{\partial u(x, t)}{\partial x_{i}} n_{j} \\
& =-M \frac{\partial u(x, t)}{\partial n}-k_{i j}^{A-I} \frac{\partial u(x, t)}{\partial x_{i}} n_{j}
\end{aligned}
$$

ただし， $q^{A}(x)$ は熱流束の法線方向成分を表す。よって温度 の法線方向勾配は次式で表すことが出来る.

$$
\frac{\partial u(x, t)}{\partial n}=-\frac{q^{A}(x, t)}{M}-\frac{k_{i j}^{A-I}}{M} \frac{\partial u(x, t)}{\partial x_{i}} n_{j}
$$

上式を式 (7) に代入することにより，異方性問題の熱流束を 導入した次の積分方程式が得られる。

$$
\begin{aligned}
& c(y) u(y, t)+\int_{\Gamma} q^{*}(x, y) u(x, t) d \Gamma+\int_{\Gamma} \frac{u^{*}(x, y)}{M} q^{A}(x, t) d \Gamma \\
& +\int_{\Gamma} \frac{u^{*}(x, y)}{M} k_{i j}^{A-I} \frac{\partial u(x, t)}{\partial x_{i}} n_{j} d \Gamma=\sum_{\ell=1}^{N+L} \alpha^{\ell}\left\{c(y) \hat{u}\left(y, z^{\ell}\right)\right. \\
& \left.+\int_{\Gamma} q^{*}(x, y) \hat{u}\left(x, z^{\ell}\right) d \Gamma-\int_{\Gamma} u^{*}(x, y) \hat{q}\left(x, z^{\ell}\right) d \Gamma\right\}
\end{aligned}
$$

式 (10)の積分方程式をすべての境界節点と内部選点に対し て適用することにより $N+L$ 個の式が得られ，マトリック ス形式で次式のようにまとめることができる.

$$
\boldsymbol{H} \boldsymbol{u}+\frac{1}{M} \boldsymbol{G} \boldsymbol{q}+\frac{1}{M} \boldsymbol{G} \boldsymbol{K} \boldsymbol{u}=[\boldsymbol{H} \hat{U}-\boldsymbol{G} \hat{\boldsymbol{Q}}] \boldsymbol{\alpha}
$$

ただし，Kは次式で表される $(N+L)$ の正方マトリックス である。

$$
\boldsymbol{K}=k_{i j}^{A-I} n_{j} \boldsymbol{F}_{x_{i}} \boldsymbol{F}^{-1}
$$

ここでさらに，未知係数 $\alpha^{\ell}$ を求める. 式 (4) が全ての境界 節点と内部選点に対して成り立つと仮定すると未知係数 $\alpha^{\ell}$ 求めることができるが, 温度の座標偏微分 $\partial^{2} u(x, t) / \partial x_{m} \partial x_{n}$ と時間微分 $\dot{u}(x, t)$ について，さらに評価が必要である。ま ず，温度の座標偏微分に対しては，近似関数を用いて次式の ように評価することができる。

$$
\boldsymbol{u}_{x_{m}}=\boldsymbol{F}_{x_{m}} \boldsymbol{F}^{-1} \boldsymbol{u}
$$

同様に, 温度の 2 階座標偏微分は温度の 1 階座標偏微分を用 いて次のように表される。

$$
\boldsymbol{u}_{x_{m} x_{n}}=\boldsymbol{F}_{x_{n}} \boldsymbol{F}^{-1} \boldsymbol{u}_{x_{m}}
$$

上式と式 (13)より, 温度の 2 階座標偏微分を温度 $u(x, t)$ と 近似関数 $f\left(x, z^{\ell}\right)$ の関数として近似することができる.

$$
\boldsymbol{u}_{x_{m} x_{n}}=\boldsymbol{F}_{x_{n}} \boldsymbol{F}^{-1} \boldsymbol{F}_{x_{m}} \boldsymbol{F}^{-1} \boldsymbol{u}
$$

また，温度の時間微分に関しては差分近似を適用することに より評洒できる。このとき，1ステップ目は直線近似の後退 差分近似， 2 ステップ以降は二次曲線後退差分近似を適用す る。前時間ステップの DRM 選点における温度から計算され る量を見かけの初期条件として計算を進める.

以上の理論により, 各タイムステップにおける $N+L$ 個の 境界上の未知量と領域内部の未知温度を, $N+L$ 個の連立方 程式を解くことにより求めることができる.

\section{3. 数值解析例と考察}

Fig.1 に示す正方形モデルを考え, 境界全体を均等に 32 個の 2 次要素を用いて分割する。内部選点は図示のように 一様に 225 点配置する. 全境界において温度 $u=0\left[{ }^{\circ} \mathrm{C}\right]$ と ᄂ, 初期温度は $T\left(x_{1}, x_{2}, 0\right)=100 \sin \left(\pi x_{1}\right) \sin \left(\pi x_{2}\right)\left[{ }^{\circ} \mathrm{C}\right]$ であ ると仮定する．直交異方性を仮定し， $k_{11}=120[\mathrm{~W} / \mathrm{mK}]$, $k_{12}=0.0[\mathrm{~W} / \mathrm{mK}], k_{22}=60[\mathrm{~W} / \mathrm{mK}]$ とする。また，密度 $\rho=7800\left[\mathrm{~kg} / \mathrm{m}^{3}\right]$, 比熱 $c=440[\mathrm{~J} / \mathrm{kgK}]$ とする. 近似関数に は Compactly Supported Radial Basis Function ${ }^{(2)(3)} の C^{2}$ 級, $C^{4}$ 級, Thin plate sprine, High order thin plate sprine, Multiquadric, $1+r^{n}$ の関数を用いた。タイムステップ幅は $\Delta t=1[\mathrm{~s}]$, Compactly Supported Radial Basis Functionで用いるサポート半 径は $a=1.42[\mathrm{~m}]$, Multiquadric で用いる定数は $c=0.2$ で計 算を行った。

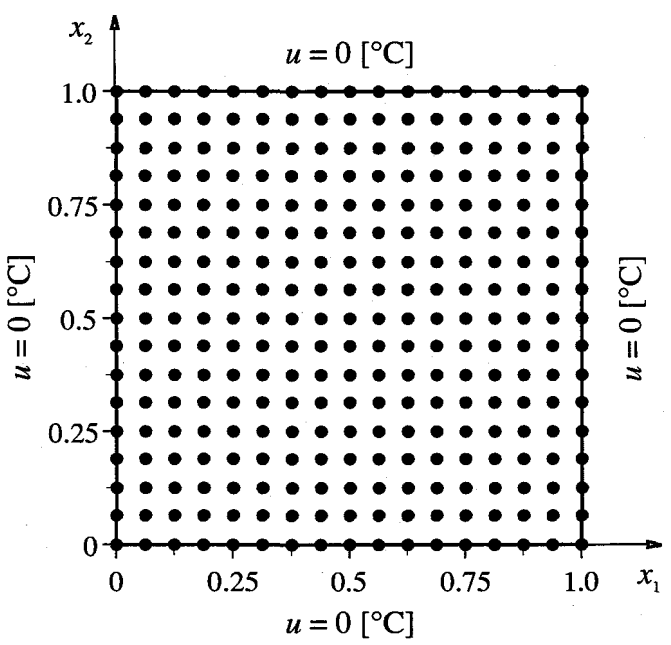

Fig. 1 Analysis model and discretization

Table 1 に $t=250[\mathrm{~s}]$ における $x_{2}=0.5[\mathrm{~m}]$ での解析結果 と厳密解との相対誤差を示す. どの近似関数を用いた場合で も精度の良い結果が得られていることがわかる。また，他の 時間でも両者がよく一致していることを確認している.

Table 1 Relative error on $x_{2}=0.5[\mathrm{~m}]$

\begin{tabular}{|c|c|}
\hline Approximate function & Relative error [\%] \\
\hline \hline${\text { CSRBF } C^{2} \text { 級 }}^{4}$ & 0.019618155 \\
\hline CSRBF $C^{4}$ 級 & 0.002712192 \\
\hline Thin plate sprine & 0.071490751 \\
\hline High order thin plate sprine & 0.004225557 \\
\hline Multiquadric & 0.007544196 \\
\hline $1+r^{2}+r^{3}$ & 0.020045447 \\
\hline $1+r^{2}+r^{3}+r^{4}$ & 0.020317743 \\
\hline $1+r^{2}+r^{3}+r^{4}+r^{5}$ & 0.050917634 \\
\hline $1+r^{2}+r^{3}+r^{4}+r^{5}+r^{6}$ & 0.044637589 \\
\hline
\end{tabular}

\section{参考文献}

(1) 田中正隆, 松本敏郎, 中村正行: 境界要素法, 培風館, 1991.

(2) P.W. Partridge, C.A. Brebbia, L.C. Wrobel: The Dual Reciprocity Boundary Element Method, Computational Mechanics Publications, 1992.

(3) C.S. Chen, C.A. Brebbia, H. Power: Commun. Numer. Meth. Engng.,15, 1999, pp. 137-150.

(4) 田中正隆, 松本敏郎, 須田裕輔, 高桑晋 : 日本機械学会論 文集 (A 編)，68-676 (2002)，pp.1702-1707. 